\title{
Evolution of tuberculosis/HIV co-infection in California during the HAART Era, 1996-2007
}

\author{
John Metcalfe ${ }^{1 *}$, Matt Facer ${ }^{2}$, Mark Damesyn ${ }^{2}$, Qiang Xia ${ }^{2}$, James Watt ${ }^{3}$, Julia Hill ${ }^{3}$, Philip Hopewell ${ }^{1}$, \\ Janice Westenhouse ${ }^{3}$, Jennifer Flood ${ }^{3}$ \\ From $16^{\text {th }}$ International Symposium on HIV and Emerging Infectious Diseases \\ Marseille, France. 24-26 March 2010
}

\section{Background}

California reports the highest annual number of tuberculosis (TB) cases and over $12 \%$ of all persons living with HIV in the US. To assess changes in the intersection of these diseases, we analyzed state-wide data from both registries.

\section{Methods}

Incident cases reported to the California TB registry from 1996 to 2007, inclusive, were cross-matched with the state HIV/AIDS registry. Incidence rates of TB with and without HIV co-infection were analyzed for changes in trend. Sociodemographic, clinical characteristics, and treatment outcomes were examined.

\section{Results}

$2,392(6 \%)$ of $39,718 \mathrm{~TB}$ cases during the study period were matched in the state AIDS registry. From 1996 to 2006, annual TB incidence among persons with HIV declined from $368 / 100,000$ to $73 / 100,000$, and without HIV declined from $12.7 / 100,000$ to $7.3 / 100,000$. Comparing the period 1996-2000 with 2001-2007, the proportion of TB/HIV cases increased among Hispanics $(48 \%$ to $57 \%$; $p<.001)$, foreign born $(46 \%$ to $63 \%$; $\mathrm{p}<.001)$, and women ( $14 \%$ to $18 \%$; $\mathrm{p}=.06)$, and decreased among Blacks ( $28 \%$ to $21 \%$; $\mathrm{p}<.001)$. Maleto-male sexual contact $(44 \%$ to $41 \%$; $\mathrm{p}<.01)$ and injection drug use $(21 \%$ to $15 \% ; \mathrm{p}<.01)$ decreased, and high-risk heterosexual contact ( $9 \%$ to $16 \%$; p <.01) increased as HIV transmission routes. $77 \%$ of all foreign born patients with TB/HIV co-infection originated from Mexico or Central America; the median time from immigration to TB diagnosis was 10.7 (IQR 4-19) years.
CD4 count at TB diagnosis (median 78 (IQR 30-167)) was available for $54 \%$ of patients. Patients with HIV coinfection were more likely to be sputum smear-positive (OR 1.17 (95\% CI 1.08-1.28). Both isoniazid resistance ( $5 \%$ to $7 \% ; \mathrm{p}=.07)$ and pyrazinamide monoresistance $(6 \%$ to $8 \% ; \mathrm{p}=.01)$ increased over time in $\mathrm{TB} / \mathrm{HIV}$ cases but not in cases without HIV. In multivariate analysis, Hispanic ethnicity, older age, and injection drug use were inversely associated with treatment success among TB/HIV cases.

\section{Discussion}

In California, the epidemiology of TB/HIV co-infection in the post-HAART era has shifted towards persons of foreign birth, women, Hispanics, and those who acquired HIV through heterosexual sex. In addition, drug resistance has increased in TB/AIDS cases. These changes should be considered in focusing TB and HIV disease prevention and treatment efforts.

\section{Author details}

'UCSF, San Francisco, USA. ${ }^{2}$ Office of AIDS, California Department of Public Health, San Francisco, USA. ${ }^{3}$ TB Control Unit, California Department of Public Health, Richmond, USA.

Published: 11 May 2010

doi:10.1186/1742-4690-7-S1-01

Cite this article as: Metcalfe et al:: Evolution of tuberculosis/HIV coinfection in California during the HAART Era, 1996-2007. Retrovirology 2010 7(Suppl 1):01.

* Correspondence: john.metcalfe@ucsf.edu

${ }^{1}$ UCSF, San Francisco, USA 